\title{
RESEARCH
}

Open Access

\section{Full-length and C-terminal neurogranin in Alzheimer's disease cerebrospinal fluid analyzed by novel ultrasensitive immunoassays}

Annika Öhrfelt ${ }^{*}$ (D), Julien Dumurgier ${ }^{2}$, Henrik Zetterberg ${ }^{1,3,4,5}$, Agathe Vrillon ${ }^{2}$, Nicholas J. Ashton 1,6,7,8, Hlin Kvartsberg ${ }^{1,3}$, Elodie Bouaziz-Amar ${ }^{9}$, Jacques Hugon ${ }^{2}$, Claire Paquet ${ }^{2}$ and Kaj Blennow ${ }^{1,3}$

\begin{abstract}
Background: Neurogranin $(\mathrm{Ng})$ is a neuron-specific and postsynaptic protein that is abundantly expressed in the brain, particularly in the dendritic spine of the hippocampus and cerebral cortex. The enzymatic cleavage of $\mathrm{Ng}$ produces fragments that are released into cerebrospinal (CSF), which have been shown to be elevated in Alzheimer's disease (AD) patients and predict cognitive decline. Thus, quantification of distinctive cleavage products of $\mathrm{Ng}$ could elucidate different features of the disease.

Methods: In this study, we developed novel ultrasensitive single molecule array (Simoa) assays for measurement of full-length neurogranin (FL-Ng) and C-terminal neurogranin (CT-Ng) fragments in CSF. The Ng Simoa assays were evaluated in CSF samples from AD patients $(N=23)$, mild cognitive impairment due to AD (MCI-AD) $(N=18)$, and from neurological controls $(N=26)$.

Results: The intra-assay repeatability and inter-assay precision of the novel methods had coefficients of variation below 7\% and 14\%, respectively. CSF FL-Ng and CSF CT-Ng median concentrations were increased in AD patients $(6.02 \mathrm{ng} / \mathrm{L}, P<0.00001$ and $452 \mathrm{ng} / \mathrm{L}, P=0.00001$, respectively) and in patients with $\mathrm{MCl}-\mathrm{AD}(5.69 \mathrm{ng} / \mathrm{L}, P<0.00001$ and $566 \mathrm{ng} / \mathrm{L}, P<0.00001)$ compared to neurological controls $(0.644 \mathrm{ng} / \mathrm{L}$ and $145 \mathrm{ng} / \mathrm{L})$. The median CSF ratio of $\mathrm{CT}-\mathrm{Ng} / \mathrm{FL}-\mathrm{Ng}$ were decreased in $\mathrm{AD}$ patients (ratio $=101, P=0.008$ ) and in patients with MCl-AD (ratio $=115, P=$ 0.016) compared to neurological controls (ratio $=180$ ). CSF of FL-Ng, CT-Ng, and ratio of CT-Ng/FL-Ng could each significantly differentiate AD patients from controls (FL-Ng, AUC =0.907; CT-Ng, AUC = 0.913; CT-Ng/FL-Ng, AUC = 0.775 ) and patients with MCl-AD from controls ( FL-Ng, AUC = 0.937; CT-Ng, AUC =0.963; CT-Ng/FL-Ng, AUC = 0.785).

\footnotetext{
* Correspondence: annika.ohrfelt@neuro.gu.se

${ }^{1}$ Department of Psychiatry and Neurochemistry, Institute of Neuroscience and Physiology, The Sahlgrenska Academy at the University of Gothenburg,

Sahlgrenska University Hospital/Mölndal, SE-431 80 Mölndal, Sweden

Full list of author information is available at the end of the article
}

(c) The Author(s). 2020 Open Access This article is licensed under a Creative Commons Attribution 4.0 International License, which permits use, sharing, adaptation, distribution and reproduction in any medium or format, as long as you give appropriate credit to the original author(s) and the source, provide a link to the Creative Commons licence, and indicate if changes were made. The images or other third party material in this article are included in the article's Creative Commons licence, unless indicated otherwise in a credit line to the material. If material is not included in the article's Creative Commons licence and your intended use is not permitted by statutory regulation or exceeds the permitted use, you will need to obtain permission directly from the copyright holder. To view a copy of this licence, visit http://creativecommons.org/licenses/by/4.0/ The Creative Commons Public Domain Dedication waiver (http://creativecommons.org/publicdomain/zero/1.0/) applies to the data made available in this article, unless otherwise stated in a credit line to the data. 
(Continued from previous page)

Conclusions: Assessments of the FL-Ng and CT-Ng levels in CSF with the novel sensitive immunoassays provide a high separation of AD from controls, even in early phase of the disease. The novel $\mathrm{Ng}$ assays are robust and highly sensitive and may be valuable tools to study synaptic alteration in AD, as well as to monitor the effect on synaptic integrity of novel drug candidates in clinical trials.

Keywords: Alzheimer's disease, Biomarkers, Cerebrospinal fluid, Mild cognitive impairment, Neurogranin, Single molecule array, SNAP-25, Synaptic, Synaptotagmin-1

\section{Background}

Alzheimer's disease (AD) is the most common cause of dementia. The disease is characterized by the accumulation of extracellular amyloid- $\beta$ (A $\beta)$ plaques, intraneuronal neurofibrillary tangles (NFT), along with substantial neuronal degeneration and synaptic loss [1]. Numerous studies have consistently shown that the core AD cerebrospinal fluid (CSF) biomarkers ( $A \beta_{1-42}, T$-tau, and P-tau) have a high diagnostic accuracy in AD dementia and also in preclinical stages of disease [2, 3]. In recent years, many synaptic proteins, including neurogranin (Ng), synaptosomal-associated protein 25 (SNAP25 ), and synaptotagmin-1, have been suggested to be biomarkers reflecting synaptic degeneration and synaptic loss. The CSF levels of these synaptic proteins are markedly elevated in $\mathrm{AD}$ dementia, and mild cognitive impairment with dementia due to AD (MCI-AD) [4-8]. Furthermore, Portelius et al. have shown a link between CSF Ng levels and neuropathological lesions including neuritic plaques and levels of NFT with Braak stages highlighting its link to the pathophysiology of $\mathrm{AD}$ [9]. Synaptic pathology occurs early in the AD brain $[10,11]$ and have shown to be reduced in hippocampus and cortical regions, while unchanged in cerebellum, a nonaffected AD region [12-14]. The synaptic functioning is the support of cognition and therefore synaptic degeneration and synaptic loss might be much closer related to cognitive decline than the other pathological hallmarks of $\mathrm{AD}[10,11,15]$.

$\mathrm{Ng}$ is a 78-amino-acid (aa)-long postsynaptic protein which is highly expressed in dendritic spines in the central nervous system (CNS) $[16,17]$ and plays a pivotal role in the synaptic plasticity $[18,19]$. Synaptic activity, mediated by $\mathrm{Ca}^{2+}$ influx, regulates synaptic plasticity through the calcium-binding protein calmodulin [19], which at high concentrations of $\mathrm{Ca}^{2+}$ activates several enzymes that are essential for long-term potentiation (LTP) $[20,21]$. At low intra-neuronal levels of $\mathrm{Ca}^{2+}$, calmodulin associates to the IQ motif (aa 33-43) (IQASFR GHMAR) of $\mathrm{Ng}[22,23]$ that are thought to lower the threshold for the induction of LTP [20]. In contrast, postsynaptic activation raises the local concentration of $\mathrm{Ca}^{2+}$, leading to phosphorylation of a serine residue (Ser36) within the IQ motif, rendering the binding to calmodulin impossible $[24,25]$. Thus, LTP is initiated by transiently $\mathrm{Ca}^{2+}$ influx inducing $\mathrm{Ng}$ dissociation from calmodulin and is essential for establishment of memory and cognition in hippocampal neurons $[17,20,26]$. In the pre-synapse, synaptotagmin-1 and SNAP-25 are two key players for properly synaptic vesicle exocytosis mediated neurotransmitter release and synaptic activation [27-30]. Postsynaptic exocytosis machinery failure may consequently account for neuronal postsynaptic disturbances, and vice versa, that might cause synaptic malfunctioning experienced in $\mathrm{AD}[29,31]$.

We have previously shown by combining immunoenrichment and mass spectrometry that $\mathrm{Ng}$ is cleaved into a series of $\mathrm{C}$-terminal peptides before release into the CSF [4, 32]. Most of the identified peptides are in close proximity of the C-terminal end of the IQ motif of $\mathrm{Ng}$, and terminate at aa 75,76 , or 78 [32]. Recently, we identified two enzymes, Calpain-1 and prolyl endopeptidase, that are capable to generate some of the $\mathrm{Ng} \mathrm{C}$ terminal peptides found in CSF [32, 33]. So far, our inhouse designed quantitative immunoassays have only included antibodies against the C-terminal half of $\mathrm{Ng}$ (CT$\mathrm{Ng}$ ) lacking IQ motif $[4,9,32,34]$. All these studies have consistently shown increased levels of CT-Ng in AD [4, $9,32,34]$. Other assays are based on antibody combinations targeting full-length $\mathrm{Ng}$ (FL-Ng), showing similar increases in $\mathrm{AD}[35,36]$.

Elevated levels of synaptic proteins in CSF are thought to reflect the loss of synapses in AD [37, 38]. Most of the synaptic $\mathrm{AD}$ biomarkers investigated up to now, i.e., $\mathrm{Ng}$, synaptotamin-1, and SNAP-25, are present in CSF as apparently shorter fragments [5, 6, 32]. Targeting of distinctive parts of CSF proteins and post-translational modifications can shed light upon pathological aspects of disease. As an example, we showed that CSF tau fragments correlated with tau positron emission tomography (PET), suggesting that these fragments might reflect the tangle pathology [39]. Another example is the CSF ratio of $A \beta_{1-42} / A \beta_{1-40}$ that have shown to perform diagnostically better than the levels of CSF $A \beta_{1-42}$ alone [40]. Therefore, it would be of interest to investigate if normalization of the CT- $\mathrm{Ng}$ concentrations to $\mathrm{FL}-\mathrm{Ng}$ would improve the diagnostic accuracy. Despite of the fact that the C-terminal $\mathrm{Ng}$ species seems to be the vast 
majority of $\mathrm{Ng}$ species, we have shown by combining immuno-enrichment and Western blotting that $\mathrm{Ng}$ is present as a seemingly FL-Ng protein in CSF [41]. However, so far, no quantitative in-house immunoassay for assessment of human FL-Ng that includes the IQ motif in CSF samples has been available. We anticipated considerably low levels of FL-Ng in CSF, thus we employed the single molecule array (Simoa) technology to provide better sensitivity than a conventional enzyme-linked immunosorbent assay (ELISA) [42].

The aim of this study was to develop and investigate CSF FL-Ng and CT-Ng to evaluate if these Ng species, alone or in combination, can reveal features of AD pathology. Novel Simoa immunoassays quantified FL-Ng and CT-Ng in parallel in human CSF samples. We tested the hypothesis that CSF $\mathrm{Ng}$ concentrations and the ratio of CT-Ng/FL-Ng would significantly differ along the AD continuum. Furthermore, we evaluated if the CT-Ng/FL$\mathrm{Ng}$ ratio would yield an improved diagnostic accuracy for $\mathrm{AD}$ as compared to single measures of $\mathrm{CT}-\mathrm{Ng}$ and FL-Ng. We also evaluated if the CSF Ng levels have associations with the core CSF biomarkers, presynaptic CSF biomarkers (SNAP-25 and synaptotagmin-1) and cognition, as measured by the Mini-Mental State Examination (MMSE).

\section{Methods}

\section{CSF samples in the clinical study}

In this cross-sectional study design, FL-Ng and CT$\mathrm{Ng}$ levels in CSF were measured in a clinical patient cohort consisting of patients with $\mathrm{AD}(N=23)$, MCIAD $(N=18)$, and neurological controls $(N=26)$. The clinical and demographic characteristics and the biomarker CSF levels of the AD core biomarkers for the cohort have been partially reported previously [6] and further detailed below. At the Center of Cognitive at Lariboisière Fernand-Widal University Hospital APHP, patients underwent a thorough clinical examination involving personal medical and family histories, neurological examination, neuropsychological assessment, and lumbar puncture with CSF biomarker analysis. The diagnosis for each patient was made by neurologists considering CSF results and according to validated clinical diagnostic criteria for AD [43], MCI$\mathrm{AD}[44,45]$, subjective cognitive impairment [46], and psychiatric disorder (DSM-IV). The CSF samples of the study were selected after a second validation step by a neurologist (CP) and a biochemist (EAB). Patients were not included in the study if a consensus diagnosis has not been achieved. This procedure resulted in the selection of CSF samples from subjects with MCI-AD, $\mathrm{AD}$, and neurological controls (no neurodegenerative disorders).

\section{Analysis of CSF core biomarkers}

CSF was obtained by lumbar puncture between the L3/ L4 or L4/L5 intervertebral space, and samples were immediately centrifuged at $1800 \mathrm{~g}$ for $10 \mathrm{~min}$ at $+4{ }^{\circ} \mathrm{C}$ and stored at $-80^{\circ} \mathrm{C}$ pending analysis. The $\mathrm{A} \beta_{1-42}$, T-tau, and tau phosphorylated at threonine 181 (P-tau) protein measurements were previously performed using commercially available assays from Fujirebio (INNOTEST ${ }^{\circ}$ $\beta$-AMYLOID $(1-42), \quad$ INNOTEST $^{\bullet}$ hTAU Ag, and INNOTEST $^{\oplus}$ PHOSPHO-TAU(181P) according to the manufacturer's instructions [6]. The following cut-off values were used to define a biochemical $\mathrm{AD}$ signature as supportive criteria for $\mathrm{AD}$ [43]: $\mathrm{A} \beta_{1-42}(<730 \mathrm{ng} / \mathrm{L})$, T-tau (> $340 \mathrm{ng} / \mathrm{L})$, and P-tau (> $58 \mathrm{ng} / \mathrm{L})$.

\section{Analysis of SNAP-25 and synaptotagmin-1}

The CSF levels of the pre-synaptic markers SNAP-25, synaptotagmin-1 peptide 215-223 (VPYSELGGK), and synaptotagmin-1 peptide 238-245 (HDIIGEFK) have previously been analyzed with an ELISA and a mass spectrometry-based assay [6, 7]. In this study, we investigate the relation between the CSF levels of FL-Ng and $\mathrm{CT}-\mathrm{Ng}$ and also the relation to the pre-synaptic markers.

\section{Production of anti- $\mathrm{Ng}$ antibodies and recombinant $\mathrm{Ng}$ protein}

The monoclonal NGN1, NGN2, NGN3, and NGN4 antibodies were produced by immunization of 8 -week-old $B A L B / c$ mice with KLH-conjugated peptides (Caslo, Lyngby, Denmark) in Freund's adjuvant, Complete (Sigma-Aldrich, F5881). The peptide sequence of the immunogen was Ac-(KLH)-CSKPDDDILDIPLDDPG-NH, i.e., aa 9-25 of Ng. After 2-3 dosages with the immunogen (approximately $100 \mu \mathrm{g} / \mathrm{mice}$ ) in Freund's adjuvant, Incomplete (second dose), or in phosphate-buffered saline (PBS) (third dose), the spleen was removed and $\mathrm{B}$ cells were fused with the myeloma cell line SP2/0 accordingly to standard procedures. Approximately 10 days after fusion of cells, cell media were screened for $\mathrm{Ng}$ antibodies using the unconjugated $\mathrm{Ng}$ immunogen peptide. Clones that reacted with the immunogen peptide, but not with a negative control peptide, were further grown, sub-cloned, and subsequently frozen in liquid nitrogen. The antibody specificity was tested using unconjugated $\mathrm{Ng}$ peptides (aa 9-25, aa 1-20, aa 15-34, and recombinant full-length $\mathrm{Ng}$ protein). The isotype was determined using the Pierce ${ }^{\mathrm{Tm}}$ Rapid Isotyping KitMouse, accordingly to the manufacturer's instructions. Then, the antibodies were purified using HiTrap ${ }^{\text {Tx }}$ Protein G HP columns (GE Healthcare).

The generation of monoclonal anti- $\mathrm{Ng}$ antibodies $\mathrm{Ng} 2$ and Ng36 has been described previously [4, 47]. The $\mathrm{Ng} 2$ antibody recognizes an epitope within the aa 52-63 
of $\mathrm{Ng}$ [4], while the $\mathrm{Ng} 36$ was generated with KLHconjugated peptide Ng $63-75$ as immunogen. The production of GST tag full-length $\mathrm{Ng}$ calibrator has been described previously [41].

\section{Novel Simoa assays for CSF FL-Ng and CT-Ng}

The Ng Simoa methods were established using guidelines found in the Homebrew Assay Development Guide Simoa HD-1 Analyzer \& Quanterix SR-X guide (Quanterix, Boston, MA, USA). Briefly, carboxylated capture beads (Quanterix) were activated for $30 \mathrm{~min}$ at $+2-8{ }^{\circ} \mathrm{C}$ by adding $0.3 \mathrm{~g} / \mathrm{L}(\mathrm{FL}-\mathrm{Ng})$ and $0.2 \mathrm{~g} / \mathrm{L}(\mathrm{CT}-\mathrm{Ng})$ Pierce $^{\mathrm{mm}}$ 1-ethyl-3-[3-dimethylaminopropyl] carbodiimide hydrochloride (EDC), No-Weigh ${ }^{\text {Tw }}$ Format (Thermo Scientific, A35391) to beads (Quanterix, 103207) solution of $1.4 \times$ $10^{6}$ beads $/ \mu \mathrm{L}$. Then, the beads were washed using a magnetic separator. The monoclonal capture antibodies $(0.2 \mathrm{~g} / \mathrm{L}$ of NGN4, FL-Ng assay, and $0.2 \mathrm{~g} / \mathrm{L}$ of Ng36, $\mathrm{CT}-\mathrm{Ng}$ assay) were allowed to conjugate to the activated beads for $2 \mathrm{~h}$ at $+2-8^{\circ} \mathrm{C}$. The conjugated capture beads were blocked and stored at $+2-8{ }^{\circ} \mathrm{C}$ pending analyses. The detection antibody was prepared by biotinylating the monoclonal antibody Ng2 in 40-fold-molar-excess of EZ-Link NHS-PEG4-Biotin (Thermo Scientific, 21329). Bead reagent solution was prepared by mixing helper beads (Quanterix, 103208) and antibody conjugated capture beads in a proportion of 50:50 (500 K and $500 \mathrm{~K}$ ). The beads were washed two times in PBS containing $0.05 \%$ Tween 20 and $1 \%$ bovine serum albumin (BSA) (Sigma, A7906) (0.05\%) (PBS-T) (assay diluent) and resuspended in assay diluent, leading to a total concentration of 20,000 beads $/ \mu \mathrm{L}$. All calibrators and CSF samples were analyzed in duplicate. For each run, human fulllength GST-tagged recombinant Ng calibrator, produced in-house [41], was serially diluted in assay diluent to providing a final concentration range of $312.5-2.44 \mathrm{ng} / \mathrm{L}$ and $1250-4.88 \mathrm{ng} / \mathrm{L}$ for FL-Ng assay (Capture NGN4 and Detection Ng2) and CT-Ng assay (Capture Ng36 and Detection Ng2), respectively. Detector Ng2 reagent solution was prepared by dilution of biotinylated detection antibody to $0.736 \mu \mathrm{g} / \mathrm{mL}$ in assay diluent. Both $\mathrm{Ng}$ immuno-methods were run in 2-step assay format. For the FL-Ng assay and CT-Ng assay, $100 \mu \mathrm{L}$ (neat CSF sample or diluted in 1:5 in assay buffer, respectively) and $100 \mu \mathrm{L}$ calibrator were added to the Nunc ${ }^{\mathrm{Tm}}$ 96-Well Polypropylene Storage Microplates (Thermo Scientific, 249944). Samples and calibrators were incubated for $2 \mathrm{~h}$ at $800 \mathrm{rpm}$ on a Simoa microplate shaker (Quanterix), simultaneously with $75 \mu \mathrm{L}$ detector reagent solution and $25 \mu \mathrm{L}$ bead reagent solution. Then, the post-detector washing program on the Simoa microplate washer (Quanterix) was applied. After washing, $100 \mu \mathrm{L}$ of streptavidin-conjugated $\beta$-galactosidase (SBG) (Quanterix) at $150 \mathrm{pM}$ diluted in SBG diluent (Quanterix) was added and incubated for $10 \mathrm{~min}$ at $800 \mathrm{rpm}$ on a Simoa microplate shaker. Then, the Post-SBG + Buffer B Wash 2.0 program on the Simoa microplate washer was applied. The bead pellets were allowed to dry for $10 \mathrm{~min}$ prior to analysis on a Quanterix SR-X benchtop instrument. Prior to measurements, the vials of resorufin $\beta$-Dgalactopyranoside (RBG) (Quanterix) were shaken at room temperature for $2-3 \mathrm{~h}$. The sample concentrations of CSF Ng were calculated from the four-parameter logistic standard curve. Calibration curve data from five runs were used to validate the assays. Limit of detection (LOD) was determined as 3 standard deviations above the zero calibrator. All unknown samples, standard samples, and human quality control (QC) CSF samples were run at least in duplicates.

\section{Performance of FL-Ng and CT-Ng Simoa assays}

The repeatability of the $\mathrm{Ng}$ Simoa assays was examined on anonymized human CSF samples supplied by the clinical routine section at the Clinical Neurochemistry Laboratory, The Sahlgrenska University Hospital, Mölndal, Sweden. The procedure making pools of leftover CSF aliquots were approved by the Ethical Committee at University of Gothenburg.

The intra-assay repeatability (within-run precision) and the inter-assay precision (between day repeatability) were validated by repeated measurements of human CSF $\mathrm{QC}(\mathrm{QC} 1$ and $\mathrm{QC2})$ samples at five different occasions. Analysis of variance (one-way ANOVA) was used in the estimation of the imprecision using the formulas in ISO 5725-2. Precision is reported as the inversely related imprecision measure [48].

\section{Statistical analysis}

Because most of the analytes were not normally distributed (Shapiro-Wilk test, $P<0.05$ ), non-parametric statistics were used for analysis. Data are given as median (interquartile range). Differences between more than two groups were assessed with Kruskal-Wallis test. Statistically significant results $(P<0.05)$ were followed by Mann-Whitney $U$ tests to investigate group differences. Significance values were adjusted by the Bonferroni correction for multiple tests. Receiver operating characteristic (ROC) curves were performed on each subject group on the levels of $\mathrm{Ng}$ in order to assess its diagnostic value. The area under the curve (AUC) and a 95\% confidence interval (CI) was calculated for CSF Ng using GraphPad Prism 8.01. The correlation coefficients (rho) were calculated using the Spearman two-tailed correlation test. SPSS 24 was employed for most of the statistical analyzes.

Since the controls were significantly older than the MCI-AD group, linear mixed models included CSF Ng (FL-Ng and CT-Ng, respectively) as the dependent 
variable and the diagnostic groups as a fixed variable, and age as a covariate was preliminary applied. The likelihood ratio test was used to compare the linear mixed models using SPSS 24 and the Chi-Square Calculator (https://www.fourmilab.ch/rpkp/experiments/analysis/ chiCalc.html). Because age did not affect the results of any of the linear mixed models (data not shown), the group differences were calculated as described above.

\section{Results}

\section{Characterization of $\mathrm{N}$-terminal $\mathrm{Ng}$ antibodies}

All of the in-house produced $\mathrm{N}$-terminal $\mathrm{Ng}$ antibodies (NGN1, NGN2, NGN3, and NGN4) were determined to be of mouse $\mathrm{IgG}_{1}$ isotype.

\section{Performance of FL-Ng and CT-Ng Simoa assays}

The novel Simoa assays are directed against epitopes within the C-terminal of $\mathrm{Ng}$ (CT-Ng, approximately aa 52-75) and against the $\mathrm{N}$-terminal to $\mathrm{C}$-terminal of $\mathrm{Ng}$ (FL-Ng, approximately aa 9-63). For the FL-Ng assay, intra-assay repeatability was $6 \%$ for $\mathrm{QC} 1$ and $4 \%$ for QC2, and inter-assay precision was $12 \%(\mathrm{QC} 1)$ and $14 \%$ (QC2). For the CT-Ng assay, intra-assay repeatability was 7\% (QC1) and 7\% (QC2), and inter-assay precision was $12 \%(\mathrm{QC} 1)$ and $11 \%(\mathrm{QC} 2)$. The repeatability were within acceptable ranges, i.e., intra-assay repeatability $\leq$ 10 and inter-assay precision $\leq 15$ [49]. LOD was 0.513 $\mathrm{ng} / \mathrm{L}$ for the FL-Ng assay and $0.111 \mathrm{ng} / \mathrm{L}$ for the CT-Ng assay. Individuals having lower FL-Ng levels than LOD were set to LOD (i.e., $0.513 \mathrm{ng} / \mathrm{L}$ ). Twelve control participants had FL-Ng levels below the LOD.

\section{Demographics of the clinical CSF study}

A subset of patients from [6] were included in this study; 26 neurological controls (65\% women, $43-80$ years), 18 patients with MCI-AD (72\% women, 58-83 years), and $23 \mathrm{AD}$ patients (74\% women, 52-84 years) (Table 1 ). The AD patients had significantly lower MMSE levels compared to the controls $(P<0.0001)$ and patients with
MCI-AD $(P=0.00002)$, respectively. Patients with MCI$\mathrm{AD}$ were significantly older than the controls $(P=0.007)$.

\section{CSF Ng in the clinical cohort}

The CSF levels of both FL-Ng and CT-Ng were significantly elevated in patients with MCI-AD (5.69 ng/L, $P<$ 0.00001 and $566 \mathrm{ng} / \mathrm{L}, P<0.00001$, respectively) and $\mathrm{AD}$ $(6.02 \mathrm{ng} / \mathrm{L}, P<0.00001$ and $452 \mathrm{ng} / \mathrm{L}, P=0.00001$, respectively) compared with controls $(0.644 \mathrm{ng} / \mathrm{L}$ and 145 ng/L, respectively) (Fig. 1). The CSF ratio of CT-Ng/FL$\mathrm{Ng}$ was significantly decreased in patients with MCI-AD $($ ratio $=115, P=0.016)$ and in $\mathrm{AD}($ ratio $=101, P=0.008)$ compared with controls (ratio $=180)$ (Fig. 1). In the group of controls, MCI-AD, and $\mathrm{AD}$, respectively, the median levels of CT-Ng were 225, 100, and 75 times higher than the median levels of FL-Ng.

FL-Ng and CT-Ng could differentiate AD from controls with $\mathrm{AUC}=0.907$ (95\% CI, 0.819-0.994) and AUC $=0.913$ (95\% CI, 0.913-0.993), respectively (Fig. 2). Furthermore, FL-Ng (AUC $=0.937 ; 95 \% \mathrm{CI}, 0.859-1)$ and CT-Ng (AUC $=0.963,95 \%$ CI, 0.913-1) could also differentiate MCI-AD from controls (Fig. 2). The CSF ratio of $\mathrm{CT}-\mathrm{Ng} / \mathrm{FL}-\mathrm{Ng}$ did not improve the separation either for $\mathrm{AD}$ ( $\mathrm{AUC}=0.775,95 \% \mathrm{CI}, 0.632-0.918$ ) or MCI-AD (AUC $=0.785,95 \%$ CI, 0.643-0.927) from controls (Fig. 2).

There were no statistically significant correlations between MMSE or age and the CSF levels of either FL-Ng or CT-Ng in any of the investigated groups (Table 2).

\section{The association of CSF $\mathrm{Ng}$ and other CSF biomarkers}

The CSF levels of FL-Ng and CT-Ng significantly correlated with all core biomarkers, i.e., $\mathrm{A} \beta_{1-42}$ (rho $=$ $0.655, P=0.003$ and rho $=0.782, P=0.003), \quad$ T-tau (rho $=0.739, P=0.00002$ and rho $=0.787, P<0.00001$ ), and P-tau (rho $=0.627, P=0.001$ and rho $=0.677, P=$ 0.0002 ) in the control group (Table 2). CT-Ng significantly correlated positively with P-tau (rho $=0.621$, $P=0.008$ ) in patients with MCI-AD (Table 2). FL-Ng

Table 1 Demographic data and core AD biomarker levels for the clinical study ${ }^{a}$

\begin{tabular}{llll}
\hline & Control & MCI-AD & AD \\
\hline Number (Women/Men) & $26(17 / 9)$ & $18(13 / 5)$ & $23(17 / 6)$ \\
Age (years) & $62(53-69), P=0.007^{\mathrm{c}}$ & $70(69-78), P=0.007^{\mathrm{b}}$ & $68(64-72)$ \\
MMSE & $27(25-28)$ & $27(26-28)$ & $22(16-24), P<0.00001^{\mathrm{b}}, P=0.00002^{\mathrm{c}}$ \\
$\mathrm{A} \beta_{1-42}(\mathrm{ng} / \mathrm{L})$ & $970(811-1091), P=0.00002^{\mathrm{c}}$ & $558(377-667), P<0.00002^{\mathrm{b}}$ & $496(459-568), P<0.00001^{\mathrm{b}}$ \\
T-tau $(\mathrm{ng} / \mathrm{L})$ & $182(154-207), P<0.00001^{\mathrm{C}}$ & $570(520-717), P<0.00001^{\mathrm{b}}$ & $618(527-734), P<0.00001^{\mathrm{b}}$ \\
P-tau (ng/L) & $35(30-41), P<0.00001^{\mathrm{c}}$ & $86(79-104), P<0.00001^{\mathrm{b}}$ & $90(73-108), P<0.00001^{\mathrm{b}}$ \\
\hline
\end{tabular}

${ }^{a}$ Data are given as median (interquartile range) unless otherwise indicated. Statistical differences were determined using non-parametric tests. The demographic data and the core AD biomarkers have partially previously been reported [6]

${ }^{b}$ Compared with controls

${ }^{c}$ Compared with $\mathrm{MCl}-\mathrm{AD}$ 


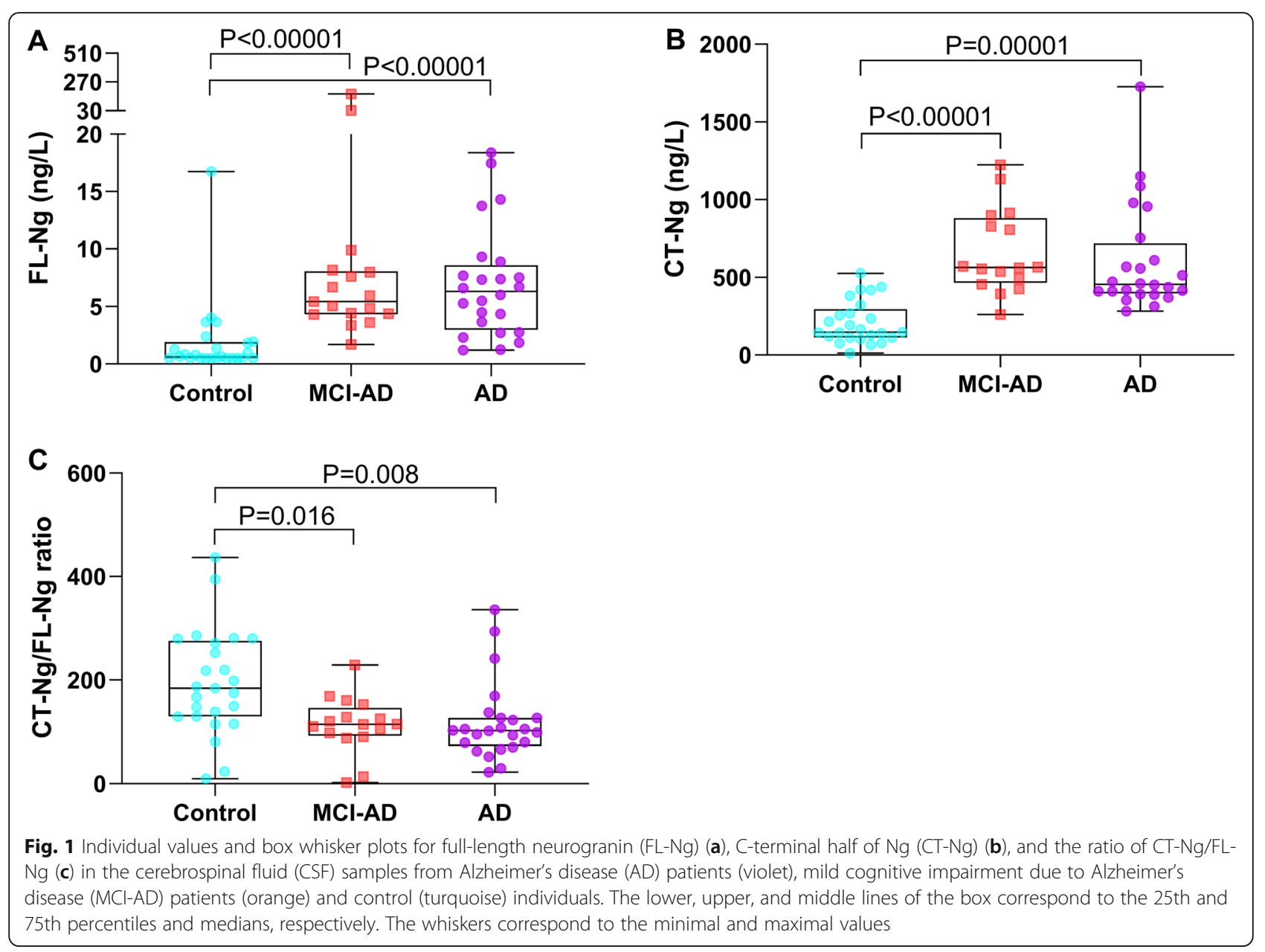

and CT-Ng significantly correlated positively with Ttau (rho $=0.500, P=0.015$ and rho $=0.664, P=0.0006$ ) in $\mathrm{AD}$ patients, while only $\mathrm{CT}-\mathrm{Ng}$ significantly correlated with P-tau (rho $=0.728, P=0.00008)$ within this group (Table 2).

The CSF level of FL-Ng and CT-Ng significantly correlated with each other (rho $=0.815, P<0.00001)$ and with all of the previously investigated pre-synaptic markers, i.e., SNAP-25 (rho $=0.601, P=0.001$ and rho $=$ $0.736, P=0.00002)$, synaptotagmin, $215-223 \quad$ (rho $=$ $0.642, P=0.0004$ and rho $=0.815, P<0.00001$ ), and synaptotagmin, 238-245 (rho $=0.640, P=0.0004$ and rho $=$ $0.805, P<0.00001)[6,7]$ in the control group (Table 3). CT-Ng significantly correlated with synaptotagmin $215-$ 223 (rho $=0.512, P=0.04$ ) and synaptotagmin $238-245$ (rho $=0.527, P=0.03$ ) in patients with MCI-AD, while FL-Ng did not correlate with any of the pre-synaptic markers within this group (Table 3). The CSF level of CT-Ng significantly correlated with of all synaptic markers FL-Ng (rho $=0.595, P=0.003)$, SNAP-25 (rho = $0.636, P=0.001$ ), synaptotagmin, $215-223$ (rho $=0.677$, $P=0.0004)$, and synaptotagmin, 238-245 (rho $=0.702$,
$P=0.0002)[6,7]$ in AD patients. The CSF levels of FL$\mathrm{Ng}$ significantly correlated positively with all synaptic markers CT-Ng (rho $=0.595, P=0.003$ ), synaptotagmin, 215-223 (rho $=0.577, P=0.004$ ), and synaptotagmin, 238-245 (rho $=0.585, P=0.003$ ) [6, 7], except from SNAP-25 in AD patients (Table 3).

\section{Discussion}

In the present study, we have evaluated two novel ultrasensitive Simoa assays for full-length neurogranin (FL-Ng) and C-terminal neurogranin (CT-Ng). Most of the current available quantitative $\mathrm{Ng}$ immunoassays $[4,9,34,50]$ contain antibodies recognizing the C-terminal half of $\mathrm{Ng}(\mathrm{CT}-\mathrm{Ng})$, and herein we confirmed that CT-Ng is a reliable CSF biomarker to discriminate cognitive impairment (AD and MCI$\mathrm{AD)}$ from controls [4, 9]. Furthermore, in a novel approach, we demonstrate that the low abundant CSF FL-Ng was also significantly elevated in both $\mathrm{AD}$ and MCI-AD as compared to controls. The CT$\mathrm{Ng}$ and FL-Ng immunoassays had similar diagnostic performances. The ratio of $\mathrm{CT}-\mathrm{Ng} / \mathrm{FL}-\mathrm{Ng}$ did not 

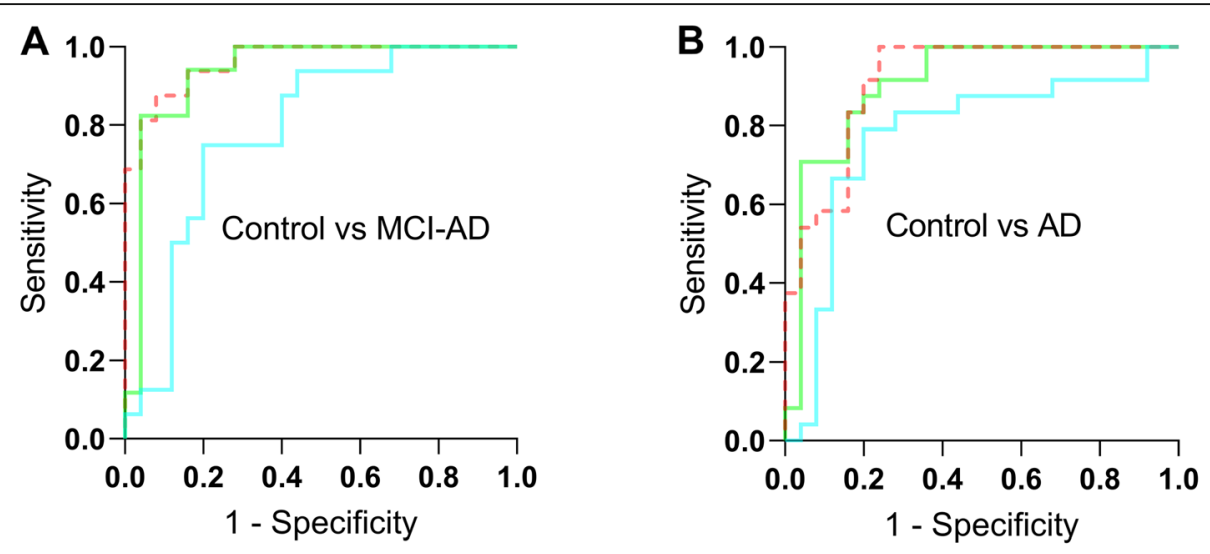

\begin{tabular}{|lll|}
\hline C & Control vs MCI-AD & Control vs AD \\
FL-Ng & AUC $0.937(0.859-1)$ & AUC $0.907(0.819-0.994)$ \\
& $\mathrm{P}<0.0001$ & $\mathrm{P}<0.0001$ \\
CT-Ng & AUC $0.963(0.913-1)$ & AUC $0.913(0.834-0.993)$ \\
& $\mathrm{P}<0.0001$ & $\mathrm{P}<0.0001$ \\
CT-Ng/FL-Ng ratio & AUC $0.785(0.643-0.927)$ & AUC $0.775(0.632-0.918)$ \\
& $P=0.002$ & $P=0.001$ \\
& & \\
\hline
\end{tabular}

Fig. 2 ROC curve analysis for full-length neurogranin (FL-Ng) (green), C-terminal half of $\mathrm{Ng}$ (CT-Ng) (orange), and the ratio of CT-Ng/FL-Ng (turquoise) in the cerebrospinal fluid (CSF) for differentiation of mild cognitive impairment due to Alzheimer's disease (MCl-AD) from controls (a) and Alzheimer's disease (AD) patients from controls (b). The area under the curve (95\% confidence interval) is shown in the incorporated table (c)

improve the separation either for AD from controls or MCI-AD from controls. Overall, our results agree with previously studies demonstrating that CSF $\mathrm{Ng}$ to be a suitable biomarker for separation of $\mathrm{AD}$ patients from controls, as well as reflecting the synaptic degeneration that occurs in brain early in the disease process $[4,9,34,35,41,50]$.

In this study, we found that the absolute CSF CT-Ng concentrations were considerably higher than the CSF FL-Ng. Since the FL-Ng assay targets aa sequences close

Table 2 Correlation between cerebrospinal fluid FL-Ng, CT-Ng, age, MMSE, and biomarker levels for the clinical study ${ }^{a}$

\begin{tabular}{|c|c|c|c|}
\hline & $\mathrm{FL}-\mathrm{Ng}$ & $\mathrm{FL}-\mathrm{Ng}$ & $\mathrm{FL}-\mathrm{Ng}$ \\
\hline & Control $(N=26)$ & MCI-AD $(N=18)$ & $\mathrm{AD}(N=23)$ \\
\hline Age & rho $=-0.136$, N.S. & rho $=0.430$, N.S. & rho $=0.061$, N.S. \\
\hline MMSE & rho $=-0.001$, N.S. & rho $=0.172$, N.S. & $\mathrm{rho}=-0.241, \mathrm{~N} . \mathrm{S}$. \\
\hline$A \beta_{1-42}$ & rho $=0.655, P=0.0003$ & rho $=0.351$, N.S. & rho $=-0.017$, N.S. \\
\hline T-tau & rho $=0.739, P=0.00002$ & rho $=0.268$, N.S. & rho $=0.500, P=0.015$ \\
\hline \multirow[t]{3}{*}{ P-tau } & rho $=0.627, P=0.001$ & rho $=0.257$, N.S. & rho $=0.391$, N.S. \\
\hline & $\mathrm{CT}-\mathrm{Ng}$ & $\mathrm{CT}-\mathrm{Ng}$ & $\mathrm{CT}-\mathrm{Ng}$ \\
\hline & Control $(N=26)$ & MCI-AD $(N=18)$ & $\mathrm{AD}(N=23)$ \\
\hline Age & rho $=-0.044$, N.S. & rho $=0.010$, N.S. & rho $=0.043$, N.S. \\
\hline MMSE & rho $=0.077$, N.S. & rho $=0.245$, N.S. & rho $=-0.132$, N.S. \\
\hline$A \beta_{1-42}$ & rho $=0.782, P=0.0003$ & rho $=0.194$, N.S. & rho $=0.032$, N.S. \\
\hline T-tau & rho $=0.787, P<0.00001$ & rho $=0.326$, N.S. & rho $=0.664, P=0.0006$ \\
\hline P-tau & rho $=0.677, P=0.0002$ & rho $=0.621, P=0.008$ & rho $=0.728, P=0.00008$ \\
\hline
\end{tabular}

${ }^{a}$ Correlations presented by Spearman's rank correlation coefficient (rho). Non-significant (N.S.) correlation coefficients $(P>0.05)$ 
Table 3 Correlation between cerebrospinal fluid FL-Ng, CT-Ng, SNAP-25, synaptotagmin, 215-223, and synaptotagmin, 238-245 levels for the clinical study ${ }^{a}$

\begin{tabular}{|c|c|c|c|}
\hline & FL-Ng & FL-Ng & FL-Ng \\
\hline & Control $(N=26)$ & $\mathrm{MCl}-\mathrm{AD}(N=18)$ & $\mathrm{AD}(N=23)$ \\
\hline $\mathrm{CT}-\mathrm{Ng}$ & rho $=0.815, P<0.00001$ & rho $=0.279$, N.S. & rho $=0.595, P=0.003$ \\
\hline SNAP-25 & rho $=0.601, P=0.001$ & rho $=0.329$, N.S. & rho $=0.306$, N.S. \\
\hline Synaptotagmin, 215-223 & rho $=0.642, P=0.0004$ & rho $=0.340$, N.S. & rho $=0.577, P=0.004$ \\
\hline \multirow[t]{3}{*}{ Synaptotagmin, 238-245 } & rho $=0.640, P=0.0004$ & rho $=0.344$, N.S. & rho $=0.585, P=0.003$ \\
\hline & CT-Ng & $\mathrm{CT}-\mathrm{Ng}$ & $\mathrm{CT}-\mathrm{Ng}$ \\
\hline & Control $(N=26)$ & $\mathrm{MCl}-\mathrm{AD}(N=18)$ & $\mathrm{AD}(N=23)$ \\
\hline $\mathrm{FL-Ng}$ & rho $=0.815, P<0.00001$ & rho $=0.279$, N.S. & rho $=0.595, P=0.003$ \\
\hline SNAP-25 & rho $=0.736, P=0.00002$ & rho $=0.458$, N.S. & rho $=0.636, P=0.001$ \\
\hline Synaptotagmin, 215-223 & rho $=0.815, P<0.00001$ & rho $=0.512, P=0.04$ & rho $=0.677, P=0.0004$ \\
\hline Synaptotagmin, 238-245 & rho $=0.805, P<0.00001$ & rho $=527, P=0.03$ & rho $=0.702, P=0.0002$ \\
\hline
\end{tabular}

${ }^{a}$ Correlations presented by Spearman's rank correlation coefficient (rho). Non-significant (N.S.) correlation coefficients $(P>0.05)$

to the $\mathrm{N}$-terminal of $\mathrm{Ng}$, these results are in agreement with our previously findings demonstrating that $\mathrm{Ng}$ is metabolized into several endogenous short C-terminal peptides that results to the markedly increased CSF levels of CT-Ng in AD patients [4]. The divergent absolute CSF FL-Ng and CT-Ng concentrations in all investigated groups may reflect that the $\mathrm{C}$-terminal peptides more easily passes the neuronal cell-membranes than the longer FL- $\mathrm{Ng}$ and/or that those $\mathrm{Ng}$ peptides indeed are more abundant, especially in AD. We recently identified that $\mathrm{Ng}$ is cleaved in the middle of IQ motif by Calpain-1 [33], which is an enzyme interestingly known to be upregulated in $\mathrm{AD}[51,52]$ and can cause the elevated CSF levels of CT-Ng in disease. Aside from a considerably lower concentration of FL- $\mathrm{Ng}$ that in contrast to CT-Ng contains an intact IQ domain, we also found elevated FL-Ng levels in AD compared with controls. However, the very low levels of FL- $\mathrm{Ng}$, particularly in controls, might imply that $\mathrm{CT}-\mathrm{Ng}$ are more prone to be liberated into CSF than FL-Ng. Discrepancies in measured levels of $\mathrm{Ng}$ peptides can be due to the intrinsic biochemical properties of endogenous $\mathrm{Ng}$ peptides of various lengths, such as differences in isoelectric points, post-translationally modifications, and disulfide linkages. For instance, $\mathrm{Ng}$ contains four cysteines (Cys3, Cys4, Cys9, and Cys51) that in absence of reducing agents are oxidized in vitro [53]. Since the novel Simoa assay do not contain reducing agents, the putative intracellular disulfide linkages of CSF Ng might diminish the ability of the $\mathrm{Ng}$ assay antibodies from binding. We have previously found several post-translational modifications on brain $\mathrm{Ng}_{1-78}$ that include disulfide bridges between Cys3 and Cys4 or between Cys4 and Cys9 [47]. Former mutation studies of individual Cys indicates that Cys 51 preferentially forms an intramolecular disulfide bond with Cys9 [54, 55], which perhaps make it more challenging to measure CSF FL-Ng than CT-Ng with the present non-reducing assay format. However, since reducing agents can disrupt disulfide bridges also between the polypeptide chains of assay antibodies, it was not possible to rule out that intramolecular disulfide $\mathrm{Ng}$ formation could influence the quantification of CSF FL-Ng and $\mathrm{CT}-\mathrm{Ng}$.

CSF CT-Ng and CSF FL-Ng levels correlated with the levels of T-tau, P-tau, and $A \beta_{1-42}$ in the control group. While no association was found with $A \beta_{1-42}$ in MCI-AD and $\mathrm{AD}$, associations were found with tau (P-tau > Ttau) in cognitive impairment groups. Taken together, all these results support the notion that the CSF $\mathrm{Ng}$ is a sensitive AD biomarker (relationship to P-tau) that to some extent reflects general neurodegeneration (relationship to T-tau) [4, 34].

A further analysis in this study investigated the relationship between the CSF levels of the postsynaptic $\mathrm{Ng}$ and the pre-synaptic markers (SNAP-25, Synaptotagmin-1, 215-223, and Synaptotagmin-1, 238-245) [6, 7]. We found that all synaptic markers correlated with each other in the control group, while nearly all synaptic markers, except from SNAP-25 and FL-Ng, correlated with each other in the $\mathrm{AD}$ group. This might reflect that both the investigated pre-synaptic activity-related markers and postsynaptic $\mathrm{Ng}$ are associated with each other both in health and synaptic degeneration. It is merely possible to speculate on the lack of correlation of FL-Ng and SNAP-25 in AD patients. FL-Ng in contrary to CT-Ng does not correlate with P-Tau in AD, which may imply that the Ng species mirror different pathological aspects of disease. In contrast to the other synaptic proteins, SNAP-25 has both pronounced pre-synaptic functions and emerging postsynaptic roles [56, 57], and the dual release sites might affect the levels of SNAP-25. Further studies that investigate a panel of CSF synaptic markers in parallel with measure 
synapse density in the brain of a living patient via neuroimaging markers (e.g., synaptic vesicle glycoprotein $2 \mathrm{~A}$ (SV2A) PET) would be valuable in order to evaluate different aspects of the CSF synaptic markers [58].

Many of the proteins associated with the AD pathogenesis are found in truncated and post-translationally modified forms in CSF [2, 4-6, 39, 59-61]. Combinations of disease-related AD CSF protein/peptide biomarkers into a ratio have shown to increase the diagnostic performance, e.g., ratio of $A \beta_{1-42} / A \beta_{1-40}$ increases the ability to distinguish patients with $A D$ from other dementia disorders by normalization to the $A \beta$ production $\left(A \beta_{1-40}\right)$ [40]. We have previously found that $\mathrm{Ng}$ peptides to total full-length ratios for nine Cterminal peptides, investigated with immuno-enrichment and mass spectrometry, were decreased in post-mortem human brain tissue from sporadic AD compared to controls [47]. Herein, applying the novel Simoa assays, we found the CSF ratio of CT-Ng/FL-Ng significantly decreased in all the examined patients' groups compared to controls. The levels of CT-Ng and FL-Ng, respectively, separated $\mathrm{AD}$ patients from controls and MCI-AD from controls with high accuracy (AUC $>0.9$ ), while the ratio of CT-Ng/FL-Ng were substantially lower $(\mathrm{AUC}<0.8)$.

The major strength of our study is the establishment of two novel ultrasensitive Simoa immunoassays for the high-throughput assessment of different peptide species of $\mathrm{Ng}$ in CSF. The novel Simoa assays exhibit high intraassay repeatability and inter-assay precision, not exceeding a coefficient of variation of $7 \%$ and $14 \%$, respectively. Thus, the repeatability was within acceptable ranges [49] to use in larger research cohort and therapeutic trials.

\section{Limitations}

There are some limitations of our study. Firstly, previous studies have shown that CSF Ng may serve as a biomarker of cognition [4, 34, 35, 62]. In this study, however, no correlation between FL-Ng or CT-Ng with cognitive decline, indexed by MMSE, in any of the examined groups was observed. The lack of evidence for correlation between cognition and $\mathrm{Ng}$ can be due to the low number of participants within each diagnostic category. The cross-sectional design may also prevent the confirmation of CSF $\mathrm{Ng}$ as prognostic marker of cognitive decline. Furthermore, the MMSE has limitations as sensitive measures for specific cognitive domains. A cognitive test that directly evaluates executive function (e.g., Trail Making Test B, Stroop Test, Verbal Fluency Test) may have yield a greater correlation. Secondly, antibodies of our novel assays are not end-specific; thus, we could not rule out that probable longer Ng fragments beyond the antibody-defined epitopes can be quantified. Lastly, Ng peptides of various lengths can have different post-translational modifications, disulfide linkages, and isoelectric points that might affect the measured levels.

\section{Conclusions}

In summary, we have applied the ultrasensitive Simoa technology to develop two novel immunoassays for assessment of the CSF levels of FL-Ng and CT-Ng. Evaluation of these assays showed significantly increased CSF levels of FL-Ng and CT-Ng in AD compared to controls, but also in MCI-AD patients. In contrast, the ratio of $\mathrm{CT}-\mathrm{Ng} / \mathrm{FL}-\mathrm{Ng}$ was decreased in $\mathrm{AD}$ and in MCI-AD but was found to be less sensitive to detect MCI-AD and $\mathrm{AD}$ than single biomarkers. Altogether, these results add further evidence to the notion of CSF $\mathrm{Ng}$ as a reliable biomarker for $\mathrm{AD}$ and early on in the pathogenesis. The novel and robust Simoa assays will be useful tools in future investigations of synaptic changes in CSF in intervention therapeutic studies with novel disease-modifying drug candidates.

\section{Abbreviations}

aa: Amino acids; $A \beta$ : Amyloid- $\beta$; AD: Alzheimer's disease; AUC: Area under the curve; Cl: Confidence interval; CNS: Central nervous system; CSF: Cerebrospinal fluid; CT-Ng: C-terminal neurogranin; ELISA: Enzyme-linked immunosorbent assay; FL-Ng: Full-length neurogranin; LOD: Limit of detection; LTP: Long-term potentiation; MCl: Mild cognitive impairment; MMSE: Mini-Mental State Examination; NFT: Neurofibrillary tangles; Ng: Neurogranin; PBS: Phosphate-buffered saline; PET: Positron emission tomography; P-tau: Tau phosphorylated at threonine 181; QC: Quality control; ROC: Receiver operating characteristic; Simoa: Single molecule array; SNAP-25: Synaptosomal-associated protein 25; SV2A: Synaptic vesicle glycoprotein 2A; T-Tau: Total tau

\section{Acknowledgements}

Not applicable.

\section{Authors' contributions}

$A O ̈$ and $K B$ performed the study design, interpretation of the results, and writing of the manuscript draft. JD, HZ, AV, NJA, HK, EBA, JH, and CP contributed to the study concept and design and/or to critical revision of the manuscript for important intellectual content. AÖ performed the experiments and analyzed and compiled the data. All authors read and approved the final manuscript.

\section{Funding}

$\mathrm{HZ}$ is a Wallenberg Scholar supported by grants from the Swedish Research Council (\#2018-02532), the European Research Council (\#681712), Swedish State Support for Clinical Research (\#ALFGBG-720931), the Alzheimer Drug Discovery Foundation (ADDF), USA (\#201809-2016862), and the UK Dementia Research Institute at UCL. KB is supported by the Swedish Research Council (\#2017-00915), the Alzheimer Drug Discovery Foundation (ADDF), USA (\#RDAPB-201809-2016615), the Swedish Alzheimer Foundation (\#AF-742881), Hjärnfonden, Sweden (\#FO2017-0243), the Swedish state under the

agreement between the Swedish government and the County Councils, the ALF-agreement (\#ALFGBG-715986), and European Union Joint Program for Neurodegenerative Disorders (JPND2019-466-236). AÖ is supported by grants from Demensfonden, Gun och Bertil Stohnes stiftelse, Stiftelsen gamla tjänarinnor, and Åhlén-stiftelsen. Open Access funding provided by Gothenburg University Library.

\section{Availability of data and materials}

The datasets used and/or analyzed during the present study are available from the corresponding author on reasonable request. 


\section{Ethics approval and consent to participate}

The study was approved by the Ethics Committee of Paris Diderot University Hospital (Bichat Hospital). All patients or caregivers gave their written informed consents for research, which was conducted in accordance with the Helsinki Declaration. The use of de-identified leftover samples for method development and validation studies was approved by the Regional Ethical Review Board at University of Gothenburg (08-11-14).

\section{Consent for publication}

Not applicable.

\section{Competing interests}

HZ has served at scientific advisory boards for Denali, Roche Diagnostics, Wave, Samumed, Siemens Healthineers, Pinteon Therapeutics, and CogRx, has given lectures in symposia sponsored by Fujirebio, Alzecure and Biogen, and is a co-founder of Brain Biomarker Solutions in Gothenburg AB (BBS), which is a part of the GU Ventures Incubator Program. KB has served as a consultant, at advisory boards, or at data monitoring committees for Abcam, Axon, Biogen, JOMDD/Shimadzu, Julius Clinical, Lilly, MagQu, Novartis, Roche Diagnostics, and Siemens Healthineers, and is a co-founder of Brain Biomarker Solutions in Gothenburg AB (BBS), which is a part of the GU Ventures Incubator Program. The other authors declare that they have no competing interests.

\section{Author details}

${ }^{1}$ Department of Psychiatry and Neurochemistry, Institute of Neuroscience and Physiology, The Sahlgrenska Academy at the University of Gothenburg, Sahlgrenska University Hospital/Mölndal, SE-431 80 Mölndal, Sweden. ${ }^{2}$ Université de Paris, INSERM U1144, Center of Cognitive Neurology, Lariboisière - Fernand-Widal Hospital, APHP, Paris, France. ${ }^{3}$ Clinical Neurochemistry Laboratory, Sahlgrenska University Hospital, Mölndal, Sweden. ${ }^{4}$ Department of Neurodegenerative Disease, UCL Institute of Neurology, London, UK. ${ }^{5}$ UK Dementia Research Institute, London, UK. ${ }^{6}$ Wallenberg Centre for Molecular and Translational Medicine, University of Gothenburg, Gothenburg, Sweden. ${ }^{7}$ Department of Old Age Psychiatry, Institute of Psychiatry, Psychology and Neuroscience, King's College London, London, UK. ${ }^{8} \mathrm{NIHR}$ Biomedical Research Centre for Mental Health and Biomedical Research Unit for Dementia at South London and Maudsley NHS Foundation, London, UK. ${ }^{9}$ Department of Biochemistry, Lariboisière Fernand-Widal Hospital, Université de Paris, INSERMU1144, APHP, Paris, France.

Received: 13 July 2020 Accepted: 10 December 2020

Published online: 22 December 2020

\section{References}

1. Blennow K, de Leon MJ, Zetterberg H. Alzheimer's disease. Lancet. 2006; 368(9533):387-403. https://doi.org/10.1016/S0140-6736(06)69113-7.

2. Olsson B, Lautner R, Andreasson U, Ohrfelt A, Portelius E, Bjerke M, et al. CSF and blood biomarkers for the diagnosis of Alzheimer's disease: a systematic review and meta-analysis. Lancet Neurol. 2016;15(7):673-84. https://doi.org/ 10.1016/S1474-4422(16)00070-3

3. Blennow K, Hampel H, Weiner M, Zetterberg H. Cerebrospinal fluid and plasma biomarkers in Alzheimer disease. Nat Rev Neurol. 2010;6(3):131-44. https://doi.org/10.1038/nrneurol.2010.4.

4. Kvartsberg H, Duits FH, Ingelsson M, Andreasen N, Ohrfelt A, Andersson K, et al. Cerebrospinal fluid levels of the synaptic protein neurogranin correlates with cognitive decline in prodromal Alzheimer's disease. Alzheimers Dement. 2015;11(10):1180-90. https://doi.org/10.1016/j.jalz.2014. 10.009.

5. Brinkmalm A, Brinkmalm G, Honer WG, Frolich L, Hausner L, Minthon L, et al. SNAP-25 is a promising novel cerebrospinal fluid biomarker for synapse degeneration in Alzheimer's disease. Mol Neurodegener. 2014;9:53. https:// doi.org/10.1186/1750-1326-9-53.

6. Ohrfelt A, Brinkmalm A, Dumurgier J, Brinkmalm G, Hansson O, Zetterberg $\mathrm{H}$, et al. The pre-synaptic vesicle protein synaptotagmin is a novel biomarker for Alzheimer's disease. Alzheimers Res Ther. 2016;8(1):41. https:// doi.org/10.1186/s13195-016-0208-8.

7. Ohrfelt A, Brinkmalm A, Dumurgier J, Zetterberg H, Bouaziz-Amar E, Hugon J, et al. A novel ELISA for the measurement of cerebrospinal fluid SNAP-25 in patients with Alzheimer's disease. Neuroscience. 2019;420:136-44. https:// doi.org/10.1016/j.neuroscience.2018.11.038.

8. Tible M, Sandelius A, Hoglund K, Brinkmalm A, Cognat E, Dumurgier J, et al. Dissection of synaptic pathways through the CSF biomarkers for predicting Alzheimer disease. Neurology. 2020;95(8):e953-e61. https://doi.org/10.1212/ WNL.0000000000010131.

9. Portelius E, Olsson B, Hoglund K, Cullen NC, Kvartsberg H, Andreasson U, et al. Cerebrospinal fluid neurogranin concentration in neurodegeneration: relation to clinical phenotypes and neuropathology. Acta Neuropathol. 2018;136(3):363-76. https://doi.org/10.1007/s00401-018-1851-x.

10. Masliah E, Honer WG, Mallory M, Voigt M, Kushner P, Hansen L, et al. Topographical distribution of synaptic-associated proteins in the neuritic plaques of Alzheimer's disease hippocampus. Acta Neuropathol. 1994;87(2): $135-42$.

11. Terry RD, Masliah E, Salmon DP, Butters N, DeTeresa R, Hill R, et al. Physical basis of cognitive alterations in Alzheimer's disease: synapse loss is the major correlate of cognitive impairment. Ann Neurol. 1991;30(4):572-80. https://doi.org/10.1002/ana.410300410.

12. Blennow K, Bogdanovic N, Alafuzoff I, Ekman R, Davidsson P. Synaptic pathology in Alzheimer's disease: relation to severity of dementia, but not to senile plaques, neurofibrillary tangles, or the ApoE4 allele. J Neural Transm (Vienna). 1996;103(5):603-18. https://doi.org/10.1007/BF01273157.

13. Davidsson P, Blennow K. Neurochemical dissection of synaptic pathology in Alzheimer's disease. Int Psychogeriatr. 1998;10(1):11-23.

14. Reddy PH, Mani G, Park BS, Jacques J, Murdoch G, Whetsell W Jr, et al. Differential loss of synaptic proteins in Alzheimer's disease: implications for synaptic dysfunction. J Alzheimers Dis. 2005;7(2):103-17; discussion 73-80. https://doi.org/10.3233/jad-2005-7203.

15. Colom-Cadena M, Spires-Jones T, Zetterberg H, Blennow K, Caggiano A, DeKosky ST, et al. The clinical promise of biomarkers of synapse damage or loss in Alzheimer's disease. Alzheimers Res Ther. 2020;12(1):21. https://doi. org/10.1186/s13195-020-00588-4.

16. Represa A, Deloulme JC, Sensenbrenner M, Ben-Ari Y, Baudier J. Neurogranin: immunocytochemical localization of a brain-specific protein kinase C substrate. J Neurosci. 1990;10(12):3782-92.

17. Diez-Guerra FJ. Neurogranin, a link between calcium/calmodulin and protein kinase C signaling in synaptic plasticity. IUBMB Life. 2010;62(8):597606. https://doi.org/10.1002/iub.357.

18. Watson JB, Battenberg EF, Wong KK, Bloom FE, Sutcliffe JG. Subtractive CDNA cloning of RC3, a rodent cortex-enriched mRNA encoding a novel 78 residue protein. J Neurosci Res. 1990;26(4):397-408. https://doi.org/10.1002/ jnr.490260402.

19. Zhong L, Cherry T, Bies CE, Florence MA, Gerges NZ. Neurogranin enhances synaptic strength through its interaction with calmodulin. EMBO J. 2009; 28(19):3027-39. https://doi.org/10.1038/emboj.2009.236.

20. Zhong L, Gerges NZ. Neurogranin targets calmodulin and lowers the threshold for the induction of long-term potentiation. PLoS One. 2012;7(7): e41275. https://doi.org/10.1371/journal.pone.0041275.

21. Xia Z, Storm DR. The role of calmodulin as a signal integrator for synaptic plasticity. Nat Rev Neurosci. 2005;6(4):267-76. https://doi.org/10.1038/nrn1647.

22. Bahler M, Rhoads A. Calmodulin signaling via the IQ motif. FEBS Lett. 2002; 513(1):107-13. https://doi.org/10.1016/s0014-5793(01)03239-2.

23. Cheney RE, Mooseker MS. Unconventional myosins. Curr Opin Cell Biol. 1992;4(1):27-35. https://doi.org/10.1016/0955-0674(92)90055-h.

24. Gerendasy D. Homeostatic tuning of $\mathrm{Ca} 2+$ signal transduction by members of the calpacitin protein family. J Neurosci Res. 1999;58(1):107-19.

25. Huang KP, Huang FL, Jager T, Li J, Reymann KG, Balschun D. Neurogranin/ RC3 enhances long-term potentiation and learning by promoting calciummediated signaling. J Neurosci. 2004;24(47):10660-9. https://doi.org/10.1523/ JNEUROSCI.2213-04.2004

26. Garrido-Garcia A, de Andres R, Jimenez-Pompa A, Soriano P, Sanz-Fuentes $D$, Martinez-Blanco $E$, et al. Neurogranin expression is regulated by synaptic activity and promotes synaptogenesis in cultured hippocampal neurons. Mol Neurobiol. 2019;56(11):7321-37. https://doi.org/10.1007/s12035-0191593-3.

27. Geppert M, Goda Y, Hammer RE, Li C, Rosahl TW, Stevens CF, et al. Synaptotagmin I: a major Ca2+ sensor for transmitter release at a central synapse. Cell. 1994;79(4):717-27. https://doi.org/10.1016/00928674(94)90556-8.

28. Sollner T, Bennett MK, Whiteheart SW, Scheller RH, Rothman JE. A protein assembly-disassembly pathway in vitro that may correspond to 
sequential steps of synaptic vesicle docking, activation, and fusion. Cell. 1993;75(3):409-18.

29. Jahn R, Fasshauer D. Molecular machines governing exocytosis of synaptic vesicles. Nature. 2012;490(7419):201-7. https://doi.org/10.1038/nature11320.

30. Kiessling V, Kreutzberger AJB, Liang B, Nyenhuis SB, Seelheim P, Castle JD, et al. A molecular mechanism for calcium-mediated synaptotagmintriggered exocytosis. Nat Struct Mol Biol. 2018;25(10):911-7. https://doi.org/ 10.1038/s41594-018-0130-9.

31. Cuestas Torres DM, Cardenas FP. Synaptic plasticity in Alzheimer's disease and healthy aging. Rev Neurosci. 2020;31(3):245-68. https://doi.org/10.1515/ revneuro-2019-0058.

32. Kvartsberg $H$, Portelius $E$, Andreasson U, Brinkmalm G, Hellwig K, Lelental $N$, et al. Characterization of the postsynaptic protein neurogranin in paired cerebrospinal fluid and plasma samples from Alzheimer's disease patients and healthy controls. Alzheimers Res Ther. 2015;7(1):40. https://doi.org/10. 1186/s13195-015-0124-3.

33. Becker B, Nazir FH, Brinkmalm G, Camporesi E, Kvartsberg H, Portelius E, et al. Alzheimer-associated cerebrospinal fluid fragments of neurogranin are generated by Calpain-1 and prolyl endopeptidase. Mol Neurodegener. 2018; 13(1):47. https://doi.org/10.1186/s13024-018-0279-z.

34. Portelius E, Zetterberg H, Skillback T, Tornqvist U, Andreasson U, Trojanowski $J \mathrm{Q}$, et al. Cerebrospinal fluid neurogranin: relation to cognition and neurodegeneration in Alzheimer's disease. Brain. 2015;138(Pt 11):3373-85. https://doi.org/10.1093/brain/awv267.

35. Kester MI, Teunissen CE, Crimmins DL, Herries EM, Ladenson JH, Scheltens P, et al. Neurogranin as a cerebrospinal fluid biomarker for synaptic loss in symptomatic Alzheimer disease. JAMA Neurol. 2015;72(11):1275-80. https:// doi.org/10.1001/jamaneurol.2015.1867.

36. Tarawneh R, D'Angelo G, Crimmins D, Herries E, Griest T, Fagan AM, et al. Diagnostic and prognostic utility of the synaptic marker neurogranin in Alzheimer disease. JAMA Neurol. 2016;73(5):561-71. https://doi.org/10.1001/ jamaneurol.2016.0086.

37. Scheff SW, Price DA. Synaptic pathology in Alzheimer's disease: a review of ultrastructural studies. Neurobiol Aging. 2003;24(8):1029-46.

38. Masliah E, Mallory M, Alford M, DeTeresa R, Hansen LA, McKeel DW Jr, et al. Altered expression of synaptic proteins occurs early during progression of Alzheimer's disease. Neurology. 2001;56(1):127-9.

39. Blennow K, Chen C, Cicognola C, Wildsmith KR, Manser PT, Bohorquez SMS, et al. Cerebrospinal fluid tau fragment correlates with tau PET: a candidate biomarker for tangle pathology. Brain. 2020;143(2):650-60. https://doi.org/10. 1093/brain/awz346.

40. Nutu M, Zetterberg $\mathrm{H}$, Londos E, Minthon L, Nagga K, Blennow K, et al. Evaluation of the cerebrospinal fluid amyloid-beta1-42/amyloid-beta1-40 ratio measured by alpha-LISA to distinguish Alzheimer's disease from other dementia disorders. Dement Geriatr Cogn Disord. 2013;36(1-2):99-110. https://doi.org/10.1159/000353442.

41. Thorsell A, Bjerke M, Gobom J, Brunhage E, Vanmechelen E, Andreasen N, et al. Neurogranin in cerebrospinal fluid as a marker of synaptic degeneration in Alzheimer's disease. Brain Res. 2010;1362:13-22. https://doi. org/10.1016/j.brainres.2010.09.073.

42. Rissin DM, Kan CW, Campbell TG, Howes SC, Fournier DR, Song L, et al. Single-molecule enzyme-linked immunosorbent assay detects serum proteins at subfemtomolar concentrations. Nat Biotechnol. 2010;28(6):595-9. https://doi.org/10.1038/nbt.1641.

43. McKhann GM, Knopman DS, Chertkow H, Hyman BT, Jack CR Jr, Kawas CH, et al. The diagnosis of dementia due to Alzheimer's disease: recommendations from the National Institute on Aging-Alzheimer's Association workgroups on diagnostic guidelines for Alzheimer's disease. Alzheimers Dement. 2011;7(3): 263-9. https://doi.org/10.1016/j.jalz.2011.03.005.

44. Albert MS, DeKosky ST, Dickson D, Dubois B, Feldman HH, Fox NC, et al. The diagnosis of mild cognitive impairment due to Alzheimer's disease: recommendations from the National Institute on Aging-Alzheimer's Association workgroups on diagnostic guidelines for Alzheimer's disease. Alzheimers Dement. 2011;7(3):270-9. https://doi.org/10.1016/j.jalz.2011.03.008.

45. Dubois B, Feldman HH, Jacova C, Hampel H, Molinuevo JL, Blennow K, et al. Advancing research diagnostic criteria for Alzheimer's disease: the IWG-2 criteria Lancet Neurol. 2014;13(6):614-29. https://doi.org/10.1016/S1474-4422(14)70090-0.

46. Sperling RA, Aisen PS, Beckett LA, Bennett DA, Craft S, Fagan AM, et al. Toward defining the preclinical stages of Alzheimer's disease: recommendations from the National Institute on Aging-Alzheimer's Association workgroups on diagnostic guidelines for Alzheimer's disease. Alzheimers Dement. 2011;7(3): 280-92. https://doi.org/10.1016/j.jalz.2011.03.003.

47. Kvartsberg H, Lashley T, Murray CE, Brinkmalm G, Cullen NC, Hoglund K, et al. The intact postsynaptic protein neurogranin is reduced in brain tissue from patients with familial and sporadic Alzheimer's disease. Acta Neuropathol. 2019;137(1):89-102. https://doi.org/10.1007/s00401-018-1910-3.

48. Andreasson U, Perret-Liaudet A, van Waalwijk van Doorn $L$, Blennow $K$, Chiasserini $D$, Engelborghs $S$, et al. A practical guide to immunoassay method validation. Front Neurol. 2015;6:179. https://doi.org/10.3389/fneur. 2015.00179

49. Lee JW, Hall M. Method validation of protein biomarkers in support of drug development or clinical diagnosis/prognosis. J Chromatogr B Analyt Technol Biomed Life Sci. 2009;877(13):1259-71. https://doi.org/10.1016/j. jchromb.2008.11.022.

50. De Vos A, Jacobs D, Struyfs H, Fransen E, Andersson K, Portelius E, et al. Cterminal neurogranin is increased in cerebrospinal fluid but unchanged in plasma in Alzheimer's disease. Alzheimers Dement. 2015;11(12):1461-9. https://doi.org/10.1016/j.jalz.2015.05.012.

51. Saito K, Elce JS, Hamos JE, Nixon RA. Widespread activation of calciumactivated neutral proteinase (calpain) in the brain in Alzheimer disease: a potential molecular basis for neuronal degeneration. Proc Natl Acad Sci U S A. 1993;90(7):2628-32. https://doi.org/10.1073/pnas.90.7.2628.

52. Kurbatskaya K, Phillips EC, Croft CL, Dentoni G, Hughes MM, Wade MA, et al. Upregulation of calpain activity precedes tau phosphorylation and loss of synaptic proteins in Alzheimer's disease brain. Acta Neuropathol Commun. 2016:4:34. https://doi.org/10.1186/s40478-016-0299-2.

53. Sheu FS, Mahoney CW, Seki K, Huang KP. Nitric oxide modification of rat brain neurogranin affects its phosphorylation by protein kinase $\mathrm{C}$ and affinity for calmodulin. J Biol Chem. 1996;271(37):22407-13. https://doi.org/ 10.1074/jbc.271.37.22407.

54. Baudier J, Bronner C, Kligman D, Cole RD. Protein kinase C substrates from bovine brain. Purification and characterization of neuromodulin, a neuronspecific calmodulin-binding protein. J Biol Chem. 1989;264(3):1824-8.

55. Mahoney CW, Pak JH, Huang KP. Nitric oxide modification of rat brain neurogranin. Identification of the cysteine residues involved in intramolecular disulfide bridge formation using site-directed mutagenesis. J Biol Chem. 1996;271(46):28798-804. https://doi.org/10.1074/jbc.271.46.28798.

56. Hussain S, Ringsevjen H, Schupp M, Hvalby O, Sorensen JB, Jensen V, et al. A possible postsynaptic role for SNAP-25 in hippocampal synapses. Brain Struct Funct. 2019;224(2):521-32. https://doi.org/10.1007/s00429-018-1782-2.

57. Antonucci F, Corradini I, Fossati G, Tomasoni R, Menna E, Matteoli M. SNAP25, a known presynaptic protein with emerging postsynaptic functions. Front Synaptic Neurosci. 2016;8:7. https://doi.org/10.3389/fnsyn.2016.00007.

58. Heurling K, Ashton NJ, Leuzy A, Zimmer ER, Blennow K, Zetterberg H, et al. Synaptic vesicle protein $2 \mathrm{~A}$ as a potential biomarker in synaptopathies. Mol Cell Neurosci. 2019;97:34-42. https://doi.org/10.1016/j.mcn.2019.02.001.

59. Cicognola C, Satir TM, Brinkmalm G, Matecko-Burmann I, Agholme L, Bergstrom $\mathrm{P}$, et al. Tauopathy-associated tau fragment ending at amino acid 224 is generated by Calpain-2 cleavage. J Alzheimers Dis. 2020; https://doi. org/10.3233/JAD-191130.

60. Portelius E, Brinkmalm G, Tran A, Andreasson U, Zetterberg H, WestmanBrinkmalm $\mathrm{A}$, et al. Identification of novel $\mathrm{N}$-terminal fragments of amyloid precursor protein in cerebrospinal fluid. Exp Neurol. 2010;223(2):351-8. https://doi.org/10.1016/j.expneurol.2009.06.011.

61. Portelius E, Brinkmalm G, Tran AJ, Zetterberg H, Westman-Brinkmalm A, Blennow K. Identification of novel APP/Abeta isoforms in human cerebrospinal fluid. Neurodegener Dis. 2009;6(3):87-94. https://doi.org/10. 1159/000203774.

62. Headley A, De Leon-Benedetti A, Dong C, Levin B, Loewenstein D, Camargo $C$, et al. Neurogranin as a predictor of memory and executive function decline in MCl patients. Neurology. 2018;90(10):e887-e95. https://doi.org/10. 1212/WNL.0000000000005057.

\section{Publisher's Note}

Springer Nature remains neutral with regard to jurisdictional claims in published maps and institutional affiliations. 